\title{
VOTOS DE JUÍZES: EMBATES DE INTERPRETAÇÕES QUANTO À ADOÇÃO POR HOMOSSEXUAIS
}

\author{
Angela Plath da Costa*
}

RESUMO: S eguindo a perspectiva da Análise de Discurso de linha francesa, refletimos sobre o modo de constituição dos sentidos, a partir das diferentes interpretações da lei sobre a adoção por casais de homossexuais e suas relações com os acontecimentos sociais. As análises ilustram os embates entre a aplicação das normas jurídicas na esfera social e a heterogeneidade constitutiva da interpretação, que trabalha em cima não apenas do discurso da normatização, mas de qualquer manifestação discursiva.

Palavras-chave: Direito; FD; posições-sujeito; acontecimento.

\section{INTRODUÇÃO}

As reflexões deste trabalho compõem a nossa dissertação de mestrado orientada pela professora S olange Mittmann ${ }^{1}$, com enfoque nas práticas discursivas jurídicas, especificamente no âmbito do Direito de Família. Constituem o corpus de análises as sequências discursivas de um acórdão sobre a adoção por casais de homossexuais, considerado este o corpus de arquivo. O acórdão é composto pelo voto de três de-

Mestra pela UFRGS em 2009; professora da rede estadual e municipal de ensino da Grande Porto Alegre

1 A dissertação foi defendida em janeiro de 2009, intitulada "Votos de Juízes: construções de sentido sobre adoção por casais de homossexuais". 
sembargadores, em resposta ao parecer interposto pelo $\mathrm{Mi}$ nistério Público, que vetava uma adoção. O veto do Ministério Público foi negado por unanimidade, através de um rearranjo dos saberes que determinam as diferentes concepções da instituição familiar, a partir de uma das posições-sujeito constituída nesta prática discursiva, do âmbito da Formação Discursiva do Direito de Família (FD-DF). Este rearranjo contempla os deslizamentos de sentidos, que produzem desde a inclusão, até a ruptura dos saberes, o que constitui o acontecimento enunciativo.

As noções de formação discursiva, interdiscurso e posição-sujeito formam o dispositivo analítico. Nomeamos de sujeito-procurador o magistrado que representa o Ministério Público, cuja formulação emerge (filtrada) na formulação dos desembargadores. Designamos como sujeito-desembargador 1 e 3, os desembargadores cujas formulações aqui analisadas compõem o acórdão, pela ordem em que aparecem (o sujeito-desembargador 2 apenas produz o voto de concordância). Os confrontos de sentidos entre as noções de família, produzidas no discurso dos sujeitos-desembargadores e do sujeito-procurador, mostram as diferentes possibilidades de relação entre os sujeitos e os sentidos, em relação à lei, ou as conformações das posições nas quais se inscrevem os sujeitos ao produzirem interpretações distintas para a mesma lei.

Compreendemos que a reflexão, nas práticas discursivas nas quais se constituem os discursos que analisamos, contribui para a compreensão do funcionamento do Direito como Formação Ideológica, em meio ao intrincamento das Formações Discursivas que a compõem, e que produz a constituição do sujeito de Direito. O que mostra, pela configuração discursiva destas noções, o funcionamento "regional" interno e externo deste âmbito de saber. Nos discursos, emergem tanto esse funcionamento interno, como as relações com as demais regiões de saber, uma vez que o Direito busca a regulação do social em sua amplitude. 
No enfoque da Análise do Discurso, olhamos para as diferentes denominações e caracterizações de família, que compõem os discursos analisados, como a constituição discursiva da realidade que se dá através da interpretação do sujeito, a partir de sua filiação ideológica. Entendemos que é a partir da noção de família que, nesta prática discursiva, materializa-se o que é chamado, no âmbito jurídico (Ferraz Júnior, [1988]/1994), de funcionamento dogmático (ou aplicação dos dogmas às situações concretas, considerados como "verdades" inquestionáveis) e de funcionamento zetético (de onde os dogmas, tidos como "verdades" provisórias, são questionados). Dessa forma, através das análises, buscamos compreender a forma pela qual os dogmas podem ser retomados no âmbito do Direito de Família. Entendemos que, especificamente nesta prática discursiva, o sujeito-procurador inscreve-se no modo de pensar que privilegia a decisão a partir da opinião sobre o que é a família - portanto dogmático -, o que constitui a posição-sujeito dogmática. Já os sujeitos-desembargadores produzem a discussão de cunho questionador em torno de como deve ser a família - incluído no pensamento zetético - de onde se constitui a posição-sujeito zetética.

Entretanto, lembramos que, dadas as complexas relações dos sujeitos com o interdiscurso das formações discursivas a cada enunciação, nossas considerações não se reportam a uma generalização do funcionamento jurídico. Abordamos, na heterogeneidade do Direito, não " $o$ ", mas sim "um dos" modos de funcionamento dos sentidos em relação à memória, dadas as condições de produção específicas nas quais os discursos são produzidos.

\section{O FUNCIONAMENTO DISCURSIVO-EDEOLÓGICO DA FD-DF}

A referência entre as palavras e os sentidos depende do lugar que o sujeito atribui a si mesmo e ao outro na engrenagem social. Segundo Pêcheux ([1969]/1997, p. 83), 
o referente ou o sentido trata-se "de um objeto imaginário (a saber, o ponto de vista do sujeito) e não da realidade física". Através das relações sintáticas, é organizado o funcionamento sistemático da materialidade linguística que, segundo Pêcheux (idem, p. 173), articula-se ao "não-sistemático", a os processos discursivos. Esta articulação não ocorre de maneira simétrica e, por isso, a língua em sua incompletude é passível de falhas.

Do ambito jurídico (Ferraz Júnior, [1998]/1994), tem-se que a hermenêutica prevê o estabelecimento dos "sentidos básicos" para a interpretação da norma jurídica, vínculando o sistema normativo aos problemas sobre os quais se refere. Neste caso específico, os sentidos básicos referem-se à noção de família - a partir dos quais serão construídas as relações de sentidos ou a interpretação da lei, que possibilitará ou não a adoção. Portanto, o procedimento hermenêutico vincula a adoção por casais de homossexuais aos sentidos do que seja a entidade familiar.

Vemos que os "sentidos básicos" são concebidos diferentemente pelos sujeitos que interpretam a normatização. Quando concebidos pelo sujeito-procurador, família é a que decorre da união entre homem e mulher: "de acordo com a doutrina, a adoção deve imitar a família biológica, inviabilizando a adoção por parelhas do mesmo sexo". Se construídos pelos sujeito-desembargador 1 , os sentidos de família vinculam-se às uniões baseadas na afetividade, às uniões pelo amor.

Ainda no âmbito do Direito, é admitido (Ferraz Júnior, 1998]/1994) que a dogmática parte dos princípios da "inegabilidade dos pontos de partida" - os dogmas - e da "compulsoriedade de uma decisão". Diante desta inegabilidade, o funcionamento através do procedimento hermenêutico, que conduz os sentidos entre o dogma e a liberdade do interpretante, constitui o desafio de encontrar a "interpretação verdadeira", ou de conciliar os objetivos de racionalidade do saber dogmático com a sua aplicabilidade através do "atos de vontades competentes". 
Já pela Análise do Discurso, encaramos o sujeito em sua interpelação ideológica, que o torna (inconscientemente) parte da engrenagem social através de sua constituição na e pela linguagem. Sendo assim, não é o sujeito que "prende a norma a certos sentidos" escolhidos a partir de um "ato de vontade", mas ele é constituído ao se inscrever nos sentidos. É a identificação do sujeito a uma das posições existentes que o fará assumir certos sentidos como seus, na ilusão de ser deles a sua origem. A vinculação do sujeito aos sentidos, em outras palavras, é produto de sua constituição ideológica, sendo o "ato de vontade" interpretado por nós, a partir desses estudos, como a própria inscrição inconsciente do sujeito em uma das posições em confronto, produzida pelo mecanismo ideológico que faz com que a filiação assuma a aparência de escolha.

Quanto à interpretação, entendemos que o que Ferraz J únior chama de "interpretação verdadeira", aquela produzida pelo "a to da vontade competente" é, na verdade, a interpretação que resulta como a dominante nos confrontos discursivos. Assim, o ato de considerar verdadeira a interpretação dominante oculta os mecanismos produtores do seu destacamento nos confrontos discursivos em relação às demais interpretações, que são tanto a filiação ideológica dos sujeitos, como também a "autoridade" conferida.

\section{A FD-DF NA FORMAÇÃo IDEOLÓGICA DO DIREITO (FI- DIREITO)}

Pêcheux parte das noções de ideologia e de interpelação, abordadas nos estudos marxistas realizados por Althusser. O jogo de confrontos - com dominância - entre as classes corresponde, segundo Althusser, à instância políticoideológica e remete à reprodução das condições de produção, que ocorre nos Aparelhos Ideológicos de Estado, ou AIE. (Althusser, 1983, p. 85-87). 
Pêcheux retoma a questão dos AIE de Althusser para concebê-los, a partir do afrontamento dos interesses de classes em seu interior, como o lugar onde pode se dar não somente a reprodução, mas também a transformação das relações de produção (Pêcheux [1975]/1995, p. 145). Dessa forma, é produzido e reproduzido o funcionamento da Ideologia (com "i" maiúsculo), estrutura que Pêcheux caracteriza como "omni-histórica" (idem, p. 151) e inerente à natureza humana, sendo o processo natural que move a história, cujo funcionamento é dissimulado através da produção das "evidências subjetivas" (ibidem, p. 152-153) nas quais se constituem os sujeitos e os sentidos.

No interior dos AIE, o confronto entre as classes faz com que se organizem em formações em contato umas com as outras, as quais, segundo Pêcheux, Haroche e Henry ([1971]/ 2007), mantém entre si relações de antagonismo, de aliança ou de dominação, as Formações Ideológicas constituem as representações "que se relacionam mais ou menos diretamente a posições de classes em conflito umas em relação às outras”. Os autores concebem as formações discursivas (FDs) como componentes das FIs. Interligadas, as FDs correspondem à materialização da FI no plano discursivo; são elas que determinam "o que pode e deve ser dito (..) a partir de uma posição dada numa conjuntura dada” (ídem, p. 26).

Os sentidos, para os autores, emergem a partir dos processos discursivos característicos das FDs -- desenvolvidos sobre a base linguística e inscritos nas relações ideológicas de classe. Assim, a língua opaca e não transparente, por intrincar-se à exterioridade constitutiva dos sentidos, traz as evidências - fornecidas pela ideologia - de que os sentidos são aqueles e não outros. São "evidências que mascaram, sob a transparência da linguagem, aquilo que chamaremos o caráter material do sentido das palavras e dos enunciados”. (Pêcheux, [1975]/1995, p. 160). (o grifo é do autor).

A partir das características "regionais" apresentadas pelas FIs, em função das especificidades nos confrontos de 
classe por elas representados, Pêcheux as diferencia em: "o Direito, a Moral, o Conhecimento, Deus, etc" (Pêcheux [1975]/ 1995, p. 145 a 147). No interior do complexo das FIs com dominância (o interdiscurso) cuja materialidade se dá através das relações discursivas, o sujeito inscreve-se em uma posição e discursiviza as atitudes e representações daquela FI a partir da região de saberes com a qual se identifica. Assim, no discurso des te sujeito emergem as posições de classes em confronto; as relações ideológicas materializam-se discursivamente no e pelo sujeito.

Enquanto conjunto de componentes que discursivizam atitudes e representações no interior Direito como FI (que chamaremos de FI-Direito), com papéis desiguais decorrentes de suas características específicas, situamos o Direito de Família como FD. Analogicamente, identificamos a intervenção, enquanto componentes, de campos de saberes como o Direito de Família, o Direito Comercial, o Direito Civil, o Direito Ambiental, etc., todos tratando das leis que regem as relações entre os sujeitos ou destes com o meio ambiente e o meio social, mas de formas distintas. Cada um traduzindo de forma diferente os saberes da FI. Materializam-se nas práticas discursivas jurídicas as complexas relações entre as regiões de saberes, internas e externas à FI-Direito, determinando as fronteiras entre o dizível e aquilo que não pode e não deve ser dito. Ao inscreverem-se nas regiões de saberes, os sujeitos passam a ocupar lugares nas relações de classe e movimentam os discursos e sentidos dessas regiões e FIs que os atravessam, podendo repetir ou constituir novas relações ideológicas, remodelando as fronteiras instáveis da região na qual se inserem ou fornecendo elementos para colocar em jogo novos campos de saberes.

AS relações internas da FD são concebidas em meio às suas relações externas com o complexo de FDs - o interdiscurso - determinando a sua heterogeneidade e instabilidade. É o interdiscurso ou o complexo de FDs em relações de "dominação, subordinação e contradição" (Pêcheux, 1975/ 
1995), intrincadas às FIs, que fornece as "evidências discursivas fundamentais (por exemplo, sob a forma de préconstruídos e de discursos transversos)", devido à própria estrutura que retorna sobre si mesma pela interpelação do sujeito. Nos esquecimentos ( 1 e 2) do que o determinam, o sujeito retoma os saberes anteriores enquanto "sistema de evidências e de significações percebidas-aceitas-experimentadas" (idem) e os devolve ao interdiscurso que o constituiu. O que faz a FD mostrar-se como a região heterogênea que, em seu interior, abriga a contradição e a desigualdade.

$\mathrm{O}$ autor mostra que a heterogeneidade da FD dá-se em virtude do funcionamento ideológico, no qual suas fronteiras permitem a migração dos saberes. Fronteiras que, segundo Courtine (Courtine, 1981, p. 49), “se deslocam”, em virtude das relações da FD com o interdiscurso. Assim, através da re-significação dos saberes, o trânsito dos saberes pelo complexo de FDs produz a reconfiguração das FDs e o deslocar de suas fronteiras. Courtine (idem, p. 35), retomando Pêcheux, concebe a sequência discursiva em sua coerência horizontal, no nível da formulação ou intradiscurso, constitutindo um nó na rede de relações interdiscursivas. Pela dependência da FD em relação ao interdiscurso, considera indissociável o estudo dos processos discursivos internos à FD, de suas relações externas.

Indursky (2000, p. 75), retomando Pêcheux e Courtine, concebe a FD "na heterogeneidade em relação a si mesma", por abrigar em seu interior a diferença e a ambiguidade. A Forma-sujeito, segundo o autor (idem, p. 76), fragmenta-se em diferentes posições-sujeito, através das relações que Pêcheux define como de identificação, de contra-identificação (a partir da relação crítica do sujeito com os saberes da FD), ou até mesmo na forma da desidentificação, caracterizada pelo distanciamento capaz de produzitr o deslocamento do sujeito para o exterior das fronteiras da FD e o surgimento de uma nova FD. O desdobramento da Forma-sujeito faz da FD o lugar da unidade, a partir das relações de paráfrases, e 
também da heterogeneidade, dada a possibilidade de dos sentidos tornarem-se outros, através das relações polissêmicas.

\section{A INSCRIÇÃO DOS SUJEITOS NAS POSIÇÕES-SUJEITO DA FD-DP}

Em nossas análises, tomamos os processos discursivos da FD-DF para compreendê-los nas relações internas a esta região de saber, de acordo com as relações entre as posiçõessujeito, entrelaçando-se às relações externas, constituídas, nesta prática discursiva, entre a FD-DF e o complexo de FDs com dominância. Esse intrincado de relações permite que teçamos algumas considerações a respeito da reconfiguração da FD-DF e do movimento de suas fronteiras, ou seja, de sua heterogeneidade. As formulações dos enunciadores da FDDF, representados pelo sujeito-procurador e pelos sujeitosdesembargadores, trazem os discursos que ilustram os diferentes modos de identificação ao sujeito universal, através das tomadas de posição, onde são produzidos processos discursivos distintos e constituídas desde as relações parafrásticas até as relações polissêmicas de sentidos. Os confrontos de sentidos que se dão na prática discursiva analisada mostram a heterogeneidade da FD-DF, a partir da fragmentação da Forma-sujeito na posição-sujeito dogmática e na posição-sujeito zetética.

Consideramos sujeitos enunciadores o procurador e os sujeitos desembargadores 1,2 e 3 , os quais se inscrevem nessas posições de sujeito. Trabalharemos, portanto, com a posição-sujeito dogmática - que mantém relação de identificação plena aos saberes admitidos pela forma-sujeito - e com a posição-sujeito zetética. Através das análises, mostraremos o desmembramento da posição-sujeito zetética em zetética-1 pelas relações de encadeamento dos novos saberes aojá estabilizado através da relação de inclusão - e zetética-2 - pela contra-identificação aos saberes admitidos pela forma-sujei- 
to, que introduz os novos saberes através da ruptura nas redes de saberes estabilizados.

Iniciamos por alguns sentidos construídos em torno do conceito de família, o qual atravessa os discursos das posições-sujeito confrontadas no âmbito da FD-DF. Antecedendo as formulções dos sujeitos-desembargadores 1 e $3^{2}$, destacamos, primeiramente, a formulação do sujeito-procurador, emergindo (filtrada) na formulação do sujeito-Desembargador 1. Essa parte figura como trecho inicial de qualquer processo, objetivando narrar suscintamente fatos e procedimentos anteriores à situação, o que temos na sequência discursiva $(\mathrm{Sd}) 1$ :

Sustenta que: (1) há vedação legal (CC, art. 1622) ao deferimento de adoção a duas pessoas, salvo se forem casadas ou viverem em união estável; (2) é reconhecida como entidade familiar a união estável, configurada na convivência pública, contínua e duradoura e estabelecida com o objetivo de constituir família, entre homem e mulher; (3) nem as normas constitucionais nem as infraconstitucionais albergam o reconhecimento jurídico da união homossexual; (4) de acordo com a doutrina, a adoção deve imitar a família biológica, inviabilizando a adoção por parelhas do mesmo sexo. Pede provimento.

No relato inicial, o sujeito-desembargador- 1 apresenta a noção de família admitida pela posição-sujeito dogmática. Antecedida pelo conector salvo se, é explicitada a condição, no discurso da lei, sem a qual o fato da oração principal não se realiza. Ou seja, a condição para a adoção a duas pessoas é a forma de união admitida pela lei como o casamento ou a união estável.

A união admitida como família pela posição-sujeito dogmática é caracterizada como estável, pública, biológica,

2 O voto do sujeito-Desembargador 2 é de concordância com o discurso do sujeito-Desembargador 1. 
contínua e duradoura. Entendemos o efeito de fechamento dos sentidos, construído através da adjetivação, como um modo de atribuir qualidade positiva ou negativa em relação à procedência dos sentidos. Ou seja, os adjetivos constituem a representação imaginária de família a partir desta posição admitida pelo Estado e, por isso, apresentam a qualificação positiva. Positiva porque normatizada pela lei, porque é aquilo que "pode" e "deve" ser dito em relação à união familiar na FI-Direito, de onde se tem autorização para determinar os sentidos possíveis (os positivos, abrigados no discurso da lei) e os não possíveis (os negativos, excluídos do discurso da lei), que determinam o sujeito universal das FDs que a compõem.

Pela expressão família biológica, tem-se a idéia de que a união familiar possui a finalidade de continuidade da espécie, ou da geração dos filhos. Na estabilidade encontra-se o determinante da manutenção, ou seja, do cuidado com a descendência. E, finalmente, pública por ter o conhecimento (que significa o aval) da sociedade e do Estado.

O fechamento dos sentidos ou saturação, que neste caso se dá com a adjetivação positiva, deixa outros sentidos de fora, os quais também são discursivizados, mas ficando do outro lado de uma relação de oposição, cujas fronteiras são marcadas através da exclusão nem... nem.... Os sentidos de união homossexual e formada por parelhas do mesmo sexo são aqueles que mantêm relações de antagonismo com a representação imaginária de família construída pelo Estado. Encontram-se fora do abrigo das normas constituciona is e infracons tituciona is e, por isso, tornam-se carregados de uma qualificação negativa.

A posição-sujeito zetética-1, a partir da qual o discurso fará emergir a inscrição dos sujeitos-desembargadores 1,2 e 3, mais adiante é discursivisada na formulação do sujeitodesembargador-1, conforme Sd 2:

No entanto, a jurisprudência deste colegiado já se consolidou, por ampla maioria, no sentido de conferir às uniões 
entre pessoas do mesmo sexo tratamento em tudo equivalente ao que nosso ordenamento jurídico confere às uniões estáveis.

O sujeito-desembargador- 1 antecede o seu dizer com o conector no entanto, que marca a oposição aos sentidos advindos do discurso da lei. A seguir, explicita a filiação à FD-DF dos sentidos que admite. Mesmo não identificados com a Forma-sujeito, encontram-se presentes no interdiscurso da FD, mantendo relações de identificação com uma jurisprudência que faz parte da memória da FD.

Ao dizer que confere às uniões entre pessoas do mesmo sexo o tratamento em tudo equivalente às uniões estáveis, o sujeito-desembargador- 1 inscreve em uma relação de igualdade os sentidos que a posição-sujeito-dogmática deixou de fora pela relação de exclusão. E o faz valorando positivamente a união formada por casais de homossexuais. À valoração negativa da noção desse tipo de família, mobilizada pela posição-sujeito dogmática na forma da qualificação que inclui e que exclui sentidos, opõe-se a valoração positiva na formulação do sujeito-desembargador-1, construída pela relação de igualdade, a partir da posição-sujeito zetética- 1 .

Em seu discurso, este sujeito apresenta sentidos referentes à noção de família, diferentes daqueles mobilizados na formulação do sujeito-procurador, conforme Sd 3:

A união pelo amor é que caracteriza a entidade familiar e não apenas a diversidade de gêneros. E, antes disso, é o afeto a mais pura exteriorização do ser e do viver, de forma que a marginalização das relações mantidas entre pessoas do mesmo sexo constitui forma de privação do Direito à vida, bem como viola os princípios da dignidade da pessoa humana e da igualdade.

Nesta sequência discursiva, pertencente à formulação do sujeito-desembargador-1, o deslizamento se dá não pela rejeição dos saberes da FD-DF, mas pela busca de inclusão 
dos sentidos construídos no conjunto do já sedimentado. Ao se inscrever na posição-sujeito zetética- 1 , o sujeitodesembargador- 1 opõe-se ao modo como a posição-sujeito dogmática constrói as fronteiras entre os sentidos: separando aqueles que compõem dos que não compõem o sujeitouniversal da FD e admitindo apenas aqueles reconhecidos jurídicamente através das normas constitucionais e infracons titucionais.

Enquanto a posição-sujeito dogmática delimita através da expressão salvo se os sentidos possíveis (em torno da família constituída pelo casamento ou pela união estável), a posição-sujeito zetética- 1 força a entrada dos sentidos que antecede com a expressão não apenas..., a união pelo amor... no interior dessa "região do oficializado", que reconhece a família formada a partir da união entre a diversidade de gêneros. A oposição salvo se x não apenas constitui-se na marca linguística do confronto discursivo entre os saberes que irão ou não irão permanecer no interior do que é admitido pela Forma-sujeito da FD. Um confronto pela inclusão de sentidos, na forma de: Não apenas $X$ é que.... $\rightarrow$ y é que.... O que é diferente da relação entre os saberes estabelecida a partir desta mesma posição, na sequência discursiva abaixo, advinda da formulação do sujeito-Desembargador 1, conforme Sd 4: "Podese dizer que não é união estável, mas é uma entidade familiar à qual devem ser atribuídos iguais Direitos".

Aqui a relação entre os sentidos se dá na forma de: .... não é $x$, mas é $y$. A posição-sujeito zetética- 1 produziu os deslizamentos de sentidos ("x é que... e não apenas $\mathbf{y}$ ") que permitem uma nova caracterização da família, inscrita em relação de inclusão na Sd 3: a união pelo amor é que caracteriza a entidade familiar e não apenas a diversidade de gêneros. Sobre a inclusão, constrói a outra relação de sentidos a partir da nominalização: (a relação entre pessoas do mesmo sexo) não é... união estável... mas é.... entidade familiar... 
O processo discursivo, assim, materializa-se, no discurso da posição-sujeito zetética-1, na forma de um novo determinante para o funcionamento das relações familiares, que é a afetividade. Em seguida, encadeia-o às práticas de relações familiares ainda não discursivizadas no discurso jurídico: as relações entre casais de homossexuais. Após, segue-se inscrição das uniões entre homossexuais como entidade familiar. O que pode ser resumido com:

Novo funcionamento das relações familiares (pelo amor) $\rightarrow$ encadeamento (união de homossexuais é baseada no amor) $\rightarrow$ inclusão (união de homossexuais, já que baseada no amor, é entidade familiar). Ou seja, os sentidos inscrevem-se na forma de: Encadeamento $\rightarrow$ inclusão de sentidos $\rightarrow$ nova noção de família.

Os novos sentidos, dessa forma, entram na discursivização da FD-DF através de um emparelhamento com os saberes admitidos em seu interior, em relação de confronto, para serem incluídos entre as noções já existentes. Se a estrutura familiar abarca novas práticas no social, estas práticas são trazidas pela posição-sujeito zetética-1 para serem, através do encadeamento que acabamos de identificar, admitidas na caracterização de família admitida pela Forma-sujeito da FD-DF (discursivizada na Sd 1). Resumindo o que foi apontado num quadro comparativo, temos duas noções diferentes para família, a partir de cada uma das posições-sujeito:

\begin{tabular}{|c|c|c|}
\hline \multirow[t]{2}{*}{$\begin{array}{l}\text { União } \\
\text { está vel }\end{array}$} & $\begin{array}{l}\text { Posição-sujeito } \\
\text { dogmática }\end{array}$ & $\begin{array}{l}\text { A partir da convivência } \\
\text { pública, contínua e } \\
\text { duradoura, com o objetivo } \\
\text { de constituir família, } \\
\text { entre homem e mulher }\end{array}$ \\
\hline & $\begin{array}{l}\text { Posição-sujeito } \\
\text { zetética-1 }\end{array}$ & $\begin{array}{l}\text { Idem ao } \\
\text { incluindo a anterior, } \\
\text { amor além da diversidade } \\
\text { de gêneros }\end{array}$ \\
\hline
\end{tabular}


De onde se tem a seguinte nominalização para a união entre casais de homossexuais:

\begin{tabular}{|l|l|l|l|}
\hline \multicolumn{1}{|c|}{$\begin{array}{c}\text { União } \\
\text { de homossexuais }\end{array}$} & Nominalização & $\begin{array}{l}\text { Vinculação à noção } \\
\text { de família }\end{array}$ & $\begin{array}{l}\text { Vinculação à questão } \\
\text { de adoção }\end{array}$ \\
\hline $\begin{array}{l}\text { Posição- } \\
\text { sujeito } \\
\text { dogmática }\end{array}$ & $\begin{array}{l}\text { Parelhas do } \\
\text { mesmo sexo }\end{array}$ & $\begin{array}{l}\text { Identificação com } \\
\text { o determinante } \\
\text { diversidade de } \\
\text { gêneros }\end{array}$ & $\begin{array}{l}\text { Negada, pelo fato } \\
\text { de a união não } \\
\text { ser reconhecida } \\
\text { pelas normas } \\
\text { jurídicas }\end{array}$ \\
\hline $\begin{array}{l}\text { Posição- } \\
\text { sujeito } \\
\text { zetética-1 }\end{array}$ & $\begin{array}{l}\text { União entre } \\
\text { pessoas do } \\
\text { mesmo sexo }\end{array}$ & $\begin{array}{l}\text { Identificação com } \\
\text { o determinante } \\
\text { afetividade }\end{array}$ & $\begin{array}{l}\text { Admitida, por } \\
\text { haver ligação } \\
\text { entre o } \\
\text { determinante } \\
\text { afetividade e os } \\
\text { princípios da } \\
\text { dignidade e da } \\
\text { igualdade }\end{array}$ \\
\hline
\end{tabular}

\section{AS FORMAS INSCRIÇÁO DO INTERDISCURSO NA FORMULA;ÁO}

A partir do quadro acima, vemos que a adoção não é concedida ao casal de mulheres a partir da posição-sujeito dogmática, pelo fato de a união não identificar-se ao determinante admitido pelos saberes que compõem a Forma-sujeito da FD-DF: a diversidade de gêneros. Esta posição filia-se à FD-DF enquanto pré-construído, identificando-se na forma de repetição dos saberes discursivizados pela lei, que determinam como deve caracterizar-se a entidade familiar.

A segunda posição, por outro lado, admite a adoção. Também filia-se à FD-DF e traz os saberes do discurso da lei. Mas encadeando-os, de forma a produzir o deslocamento, através da nova caracterização para a noção de família (a partir da afetividade). Este deslocamento de sentidos produz o retorno do interdiscurso sobre si, conforme descrito por Pêcheux, pelo encadeamento do discurso transverso ([1975]/1997, p. 
167). Assim, se a afetividade não é admitida como determinante da noção de família a partir da posição-sujeito dogmática, encontra-se vinculada aos princípios da dignidade e da igualdade a partir da posição-sujeito zetética-1 que inscreve-a entre os saberes que compõem a FD-DF, através da articulação dos saberes advindos do interdiscurso.

Os modos de articulação dos saberes que identificamos no parágrafo anterior produzem as diferentes concepções de família que se confrontam no interior da FD-DF, ou o confronto entre a repetição e a articulação do interdiscurso, enquanto pré-construído e enquanto discurso transverso, conforme admitido pelas posições-sujeito dogmática e zetética-1, respectivamente. É como discurso transverso que a posiçãosujeito zetética- 1 aciona os sentidos anteriores, advindos da própria FD-DF, conforme Sd 5:

Estamos hoje, como muito bem ensina Luiz Edson Fachin, na perspectiva da família eudemonista, ou seja, aquela que se justifica exclusivamente pela busca da felicidade, da realização pessoal dos seus indivíduos. E essa realização pessoal pode dar-se dentro da heterossexualidade ou da homoss exualidade.

A observação desta sequência discursiva, que compõe a formulação do sujeito-Desembargador-1, inscrito na posiçãosujeito zetética-1, remete a uma anterioridade já reconhecida no âmbito da FD. Entendemos que a concepção de família eudemonista está inscrita entre os saberes da FD-DF, por ser admitida a partir de um sujeito que ocupa uma posição no interior das práticas que compõem esta região de saber, em $\mathrm{CP}$ anteriores. Assim, a argumentação, que do ponto de vista da $\mathrm{AD}$ não significa constituição de sentidos pelo sujeito, mas filiação aos saberes pré-existentes, se dá neste confronto discursivo, de dois modos. A partir da posição-sujeito dogmática, na forma de repetição do pré-construído, excluindo sentidos outros que não os da união constituída a partir da diversidade de gêneros e da estabilidade. A partir da posi- 
ção-sujeito zetética-1, articulando o discurso transverso e incluindo os outros sentidos, estabelecendo inicialmente uma relação de coexistência entre estes e aqueles com os quais se confrontam (não apenas x é que...; y é que...) para, a seguir, construir uma relação de oposição (não é x, mas é y). Como veremos mais adiante, é a partir desta relação de oposição que se dará a ruptura dos saberes, o que constituirá a posição-sujeito zetética-2. A argumentação, como inscrição nos sentidos, constitui-se no elo que permite a discursivização do fato social união e adoção por casais homossexuais dentro da abrangência da FD-DF.

Ao relacionar a noção de família aos sentidos de eudemonista, a posição-sujeito zetética- 1 qualifica-a através do advérbio exclusivamente, o qual restringe como os únicos possíveis sentidos da noção de família aqueles em torno da busca da felicidade. O efeito de restrição aqui funciona como o modo de colocar estes sentidos em relação de oposição àqueles que, primeiramente, foram confrontados através da relação de inclusão. Sintetizando o que foi dito nos parágrafos anteriores, a posição-sujeito zetética- 1 primeiro constrói a inclusão dos outros sentidos para a noção de família e de adoção. Depois produz a restrição em torno destes sentidos, para os colocar, então, em relação de oposição aos saberes admitidos pela Forma-sujeito, no interior da FD-DF, o que irá configurar a posição-sujeito zetética-2. Assim é que interpretações diferentes podem trazer aplicabilidades distintas para a mesma normatização, o que significa considerar as consequências diversas, no social, advindas das construções de sentidos dos discursos do sujeito-procurador e dos sujeitos-desembargadores.

Ainda na formulação do sujeito-desembargador 1 , emergem os saberes da FD do Direito de Família francês. Nestas outras CP, os deslizes de sentido também foram possíveis a partir das relações polissêmicas, permitindo a construção de novos sentidos e de novas posições-sujeito, conforme Sd 7: 
Com efeito, o tratamento analógico das uniões homossexuais como entidades familiares segue a evolução jurisprudencial iniciada em meados do séc. XIX no Direito francês, que culminou no reconhecimento da sociedade de fato nas formações familiares entre homem e mulher não consagradas pelo casamento.

O sujeito-desembargador 1, inscrito na posição-sujeito zetética-1, traz o tratamento analógico, que permite inscrever a união entre casais de homossexuais na concepção das entidades familiares, da mesma forma como constituiu-se pela jurisprudência do Direito francês a concepção das uniões não consagradas pelo casamento como família. A construção dos saberes, naquelas condições de produção, se deu no sentido de passar a considerar:

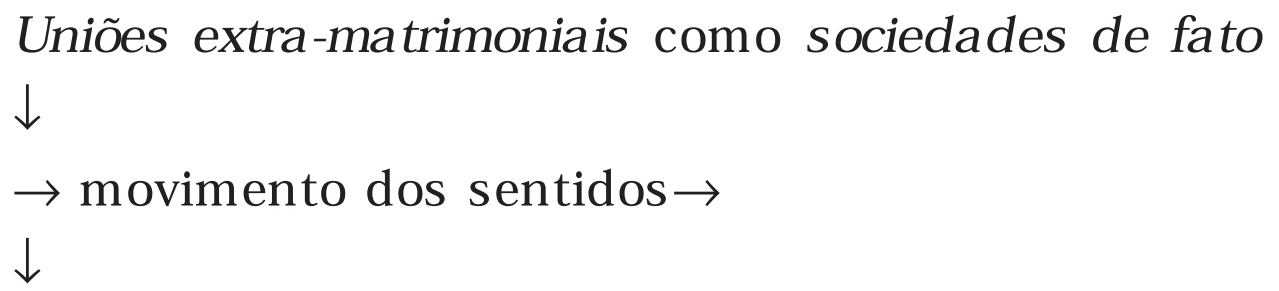

Uniões extra-matrimoniais como entidades familiares.

O movimento dos sentidos permitiu, assim, que a concepção de família passasse a abranger também as relações não consagradas pelo ritual do casamento, institucionalizado no âmbito da FD-DF. Ou seja: as uniões extra-matrimoniais deixam de ser consideradas "sociedades de fato" para serem admitidas com entidades familiares. A posição-sujeito zetética-1, identificada à anterioridade que remete a uma ruptura dos sentidos, pela analogia, busca a inclusão de novos saberes à noção, já ampliada, das entidades familiares: 
Uniões entre homossexuais como sociedades de fato $\downarrow$

$\rightarrow$ movimento dos sentidos $\rightarrow$

$\downarrow$

Uniões entre homossexuais como entidades familiares.

Estamos na região dos movimentos dos sentidos onde se encontram as fronteiras entre os deslizamentos e a ruptura, onde constitui-se a posição-sujeito zetética- 2 . Admitir a família homossexual significa a desestruturação dos parâmetros tradicionais de reconhecimento da relação familiar, a ponto de romper com as regras já estabelecidas e aceitas socialmente, representadas pelas leis vigentes. $\mathrm{Na}$ Sd 7 (acima), pela expressão segue a evolução, as relações remetem à posição-sujeito contra-identificada com a Formasujeito no Direito Francês, a qual emergiu com as construções de sentidos responsáveis pela legalização do concubinato. Ou seja, no discurso da posição-sujeito zetética1, pela analogia ao Direito francês, é buscada a legitimidade de um discurso pela sua filiação. A polissemia é autorizada, por identificar-se à posição que desestabilizou os sentidos oficiais em CP anteriores.

Se, em condições anteriores, a noção de família "descola-se" do casamento como determinante, passando a incluir as uniões extra-matrimoniais, hoje é concebido, a partir da posição-sujeito zetética-2, um novo "descolamento": entre a noção de familia e o determinante ligado à diversidade de gêneros. Entendemos a analogia com a jurisprudência do Direito francês, como o movimento de legitimação dos sentidos que infiltram-se nas "lacunas" apontadas do âmbito jurídico como parte da "incompletude" do discurso da Lei, dada a impossibilidade de abranger todo e qualquer fato social (Bobbio, 1999). A infiltração dos sentidos permite o abarcamento, no discurso jurídico, de saberes que irão compor, nesta prática discursiva, inicialmente, a inclusão, seguindo-se a ruptura 
nas redes de sentidos, para dar-se, posteriormente, talvez, a sua ampliação/transformação. Neste momento, o "outro", antes mantido fora dos limites da FD-DF, transpõe as fronteiras da FD e passa a ser incluído, senão entre os saberes que compõem a Forma-sujeito, pelo menos entre aqueles admitidos pela posição-sujeito-zetética-2, no interior da FD.

\section{CONTRA-IDENTIFICAÇÃO: A ABERTURA PARA AS RELAÇÕES DE TRANSFORMAÇÃO}

Indursky (2000, p. 84-85), reportando-se à heterogeneidade da FD, concebe que a interpelação não acontece sem falhas, já que os sentidos podem ser questionados e tornarem-se outros quando o sujeito, contra-identificado, questiona os saberes da FD. Como uma das falhas do ritual de interpelação, o autor reporta-se ao acontecimento enunciativo, que é "capturado" (idem, p. 85) no momento de instauração de uma nova posição-sujeito, capaz de fragmentar a Forma-sujeito e trazer para o interior da FD os sentidos que antes não eram admitidos naquela região de saber. A nova posição-sujeito "traz para o interior da identidade a alteridade, provocando estranhamento nas fileiras do sentido..." (ibidem).

De acordo com a concepção do autor, na prática discursiva aqui analisada, temos o surgimento da posiçãosujeito zetética- 2 como o acontecimento enunciativo que produz a divisão no interior da FD-DF, em relação aos saberes em torno da família homossexual realizando a prática da adoção. A inclusão destes saberes no interior da FD produz a fragmentação da Forma-sujeito, já que ali não são incluídos a partir da posição-sujeito dogmática.

Vemos que a identificação dos sujeitos-desembargadores à inclusão de novos saberes vincula-se à concepção de família constituída a partir da posição-sujeito na qual se 
inscrevem. Além da inclusão do "outro" dentro da legitimidade, buscada através da analogia com saberes internos à FD, temos a discursivização da posição-sujeito zetética-2, neste discurso, pelas relações deste "outro" com a região externa à FD. Lembremos que a posição-sujeito, de acordo com Pêcheux ([1975]/1995), é atravessada pelos saberes do complexo de FDs em relação, que a perpassam. No discurso da posiçãosujeito zetética-2, emergem as relações com os saberes pertencentes ao interdiscurso, conforme SD 8, que contém a formulação do sujeito-Desembargador-1: "Os estudos especializados não apontam qualquer inconveniente em que crianças sejam adotadas por casais homossexuais...".

Ao referir-se aos "estudos especializados", esta posiçãosujeito traz, para o interior da FD-DF, saberes advindos de outras FDs, neste caso, da antropologia, conforme podemos observar na Sd 34, que traz a formulação do sujeitoDesembargador 1: “... é novamente Héritier quem nos traz da antropologia um exemplo que evidencia que em organizações sociais tidas por primitivas o papel de pai nem sempre é exercido por um indivíduo do sexo masculino".

A qualificação dos saberes pertencentes à FD-antropologia como estudos especializados, confere-lhes o status do reconhecimentojurídico e aponta as relações com dominância entre o complexo de FDs. Ao dizer que estes estudos nãoapontam qualquer inconveniente..., o sujeito- desembargador-1, inscrito na posição-sujeito zetética- 2 , traz saberes antecedidos pela expressão especializados para o interior da FD-DF como autorização, advinda da FD da ciência antropológica, para o descolamento da noção de família do determinante ligado à diversidade de gêneros.

O funcionamento discursivo descrito no parágrafo anterior ilustra a interelação de dominância entre o complexo de FDs: a dominancia da FD-DF em relação à família e a dominância da FD antropológica em relação à FD-DF. Enquanto a FD-DF mantém a dominância nas relações com a 
família, por determinar as práticas possíveis em seu interior através das normas jurídicas, também se submete, a partir do discurso da posição-sujeito zetética-2, à dominância da FD-Antropologia, pelo funcionamento que se dá através do trânsito dos saberes através das fronteiras de ambas as FDs, tal como apontado em Pêcheux e mostrado através destas análises. Assim, se uma posição inscrita na outra FD "não a ponta qualquer inconveniente em que crianças sejam adotadas por casais homossexuais", estes saberes são trazidos para a FD-DF pela posição-sujeito zetética- 2 para articulá-los ao préconstruído da FD-DF e construir a formulação que inclui este tipo de união entre aquelas abarcadas pela noção de entidades familiares admitidas pela Forma-sujeito. A complexidade dos movimentos dos saberes pelo complexo de FDs, que produz a instabilidade das fronteiras da FD-DF, é ressaltada pelas nuances da relação de dominância. Se emergem as relações de dominância da FD-Antropologia em relação à FD-DF no discurso da posição-sujeito zetética-1, é porque lhe foi conferido este caráter, através da tomada de posição do sujeito que superpõe as duas FDs, ao constituir o processo discursivo.

Dessa forma temos, na FD-DF, de acordo com a inscrição dos sujeitos nos sentidos, modos diferentes de promover a aplicabilidade da lei. Construindo relações de paráfrases em relação ao pré-construído, a posição-sujeito dogmática promove a igualdade dos sujeitos sociais a partir da exclusão dos sentidos novos (das uniões não formadas a partir da diversidade de gêneros), distintos daqueles já sedimentados. Já a posição-sujeito zetética- 1 promove a aplicabilidade da lei e concebe a igualdade social justamente através do funcionamento discursivo antagônico: para tornar-se "igual", o diferente precisa ser "incluído" nas relações de identificação com a Forma-sujeito da FD-DF.

Ao abrigar em suas práticas discursivas os saberes e práticas referentes às relações familiares por meio do confronto destes dois discursos que mantém entre si relações de antagonismo, a FD-DF mostra a heterogeneidade inerente a 
esta região de saber. Os sentidos construídos a partir da posição-sujeito zetética- 2 referem-se à exclusão do determinante do gênero ou identidade sexual dos casais como capacitação para adoção. Instauram a nova posição-sujeito no interior da FD-DF, o que significa a concessão da primeira adoção para um casal de homossexuais no Brasil. Dada a heterogeneidade de uma FD admitida por Pêcheux ([1975]/1995) e Courtine (1981), vemos a entrada destes novos saberes no interior da FD-DF somente a partir das posições-sujeito zetéticas 1 e 2 . Uma vez instalados, estes saberes passam a manter outras relações de confronto com a Forma-sujeito da FD, além daquelas referentes à capacitação para adoção.

Em um discurso posterior ao que compõe o nosso corpus de estudo, referindo-se à questão da constituição de famílias homoafetivas ${ }^{3}$ e da adoção por casais de homossexuais, o sujeito-desembargador 3 formula, em uma enunciação posterior: "temos de superar a dicotomia das diferenciações das pessoas pelo sexo masculino ou feminino". (Dias, 2008) ${ }^{4}$. Ou seja, os sentidos em torno da família homoafetiva, anteriormente inscritos no lado externo da fronteira caracterizada pela expressão há vedação, passaram a fazer parte da FD-DF, instalando-se concomitantemente com aqueles permitidos pela expressão salvo se e instaurando a divergência de sentidos no interior da FD.

\section{CONSIDERAÇÕES FINAIS}

Esperamos ter ilustrado, através das análises, o modo como as práticas discursivas jurídicas produzem o funcionamento do Direito como FI quanto aos aspectos internos, re-

3 A expressão é introduzida no funcionamento discursivo-ideológico da FD-DF pelo sujeito-desembargador-3, para referir as famílias formadas por casais homossexuais.

4 Nesta formulação tomamos o sujeito-desembargador-1 como autor do âmbito do Direito. 
ferentes ao seu funcionamento sistemático, intrincados às relações externas a esta região de saber. Tanto as práticas sociais de famílias formadas pela heterossexualidade como pela homossexualidade passam a ser possíveis de obter o reconhecimento jurídico. Entretanto, somente as primeiras são reconhecidas a partir da posição-sujeito dogmática, ambas são reconhecidas pela posição-sujeito zetética-1, e somente as segundas são admitidas pela posição-sujeito zetética-2.

Essa reunião dos contrários que se confrontam promove a possibilidades distintas e antagônicas, gerenciadas pelo funcionamento da FD-DF, de certas práticas na formação social. Assim é que a constituição da família a partir do determinante da afetividade, em substituição do determinante ligado ao gênero, constitui o acontecimento enunciativo, a ruptura que causa estranhamento e alvoroço nas fileiras de saberes (Indursky, 2000 e 2003). É a ruptura a partir da proposta de substituição dos sentidos admitidos a partir da posição-sujeito dogmática, pelos sentidos admitidos a partir da posição-sujeito zetética-2.

Assim, o surcimento da posição-sujeito zetética-2, que caracteriza o acontecimento enunciativo da FD-DF, em meio aos indefinidos e instáveis lançares de interpretação, uns sobre os outros, mostra-se nesta prática discursiva. Os futuros confrontos de sentidos, de acordo com os intrincamentos entre a dominância interna e externa da FD, ao tensionarem as relações de dominância no interior da FD-DF, é que determinarão ou a transformação das práticas na família, ou a reprodução das mesmas.

A partir das análises, temos que as relações de identificação ao sujeito de Direito conferem aos indivíduos - entre eles o indivíduo homossexual - a sua capacidade jurídica de constituir a unidade familiar e de adotar, dando-lhes os direitos e as obrigações inerentes ao "bom sujeito" descrito por Pêcheux. A adoção encontra-se entre esses direitos, regulamentada também por obrigações, que conduzem os sujeitos a 
submeter-se ao que é permitido pela Forma-sujeito da FD$\mathrm{DF}$, para ser realizada como prática social.

E ntendemos que o duplo "trânsito" de reprodução/transformação entre o discursivo e o social, caracterizado nesta prática discursiva, pela regulação jurídica da prática de adoção, é ilustrado pelo intrincado de relações da FD-DF, através dos embates entre a posição-sujeito dogmática e as posiçõessujeito zetéticas 1 e 2 , na busca dos determinantes para a noção da família, cujo confronto permitirá a regularização de certos sentidos no interior da FD, em detrimento de outros. A regularização dos sentidos na FD-DF, acompanhada da sedimentação, produzirá a regularização e sedimentação dos sentidos e práticas na família, na medida em que serão definidos os papéis possíveis de serem desempenhados em seu interior, ou quais as práticas possíveis de compor os seus rituais de funcionamento, e por quais sujeitos.

Quanto à discussão sobre a adoção, partindo dos nós formados em torno do conceito de família, pudemos observar que irá mexer também com outros sentidos e fazê-los deslizar, compondo outros nós na rede de sentidos. A função da paternidade vai ser discutida como prática de relação entre os sujeitos sociais, envolvendo sentidos baseadas no ato da procriação, no afeto, no cuidado. As relações entre os sujeitos sociais são discursivizadas no interior da FD-Direito-família, através do jogo entre os sentidos para as noções família/paternidade, que irão permitir não somente a construção dos saberes capazes de legitimar as práticas de adoção, mas também outras práticas sociais familiares, entre elas a união entre os homossexuais.

Assim, os sentidos intrincam-se a outros, compondouma região de conceitos e de noções. Estes giram em torno das práticas de reprodução daquelas já existentes, a partir das interpretações que se identificam com os sentidos já oficializados, e buscam mantê-los. Ou giram em torno das práticas de transformação, pelas interpretações capazes de juntar ao pré-construído os sentidos determinados por outras regiões 
da FD, para transformá-lo. Esperamos que as reflexões aqui tecidas, sobre o jogo entre a reprodução/transformações dos sentidos e práticas, produzidos no heterogêneo funcionamento discursivo/ideológico da FD-DF, possam conduzir para reflexões a respeito da igualdade social, lançada sobre as bases (ideológicas) dos gestos de interpretação, que intrincam o discursivo e o social, dentro e fora das instáveis fronteiras de um domínio de saber.

\section{BIBLIOGRAFIA}

ALTHUSSER, Louis. (1968). Aparelhos Ideológicos de Estado: nota sobre os aparelhos ideológicos de Estado. Rio de Janeiro: Edições Graal, 1983.

BOBBIO, Norberto. Teoria do ordenamento jurídico. 10. ed. Brasília: Editora da Universidade de Brasília, 1999.

COURTINE, Jean-Jaquecs. Analyse du discours politique. Langages, n.61, juin, 1981.

DIAS, Berenice. Famílias - um adjetivo plural. Palestra na Faculdade IDC, Porto Alegre, 2008.

FERRAZ JR., Tercio S (1988). Introdução ao Estudo do Direito. 2. ed. São Paulo: Atlas, 1994.

HAROCHE, Claudine, PÊCHEUX, Michel \& HENRY, Paul. A semântica e o corte saussuriano: língua, linguagem e discurso (1971).In: BARONAS, Roberto Leiser. (org). Análise do Discurso, apontamentos para uma história da noção de Formação Discursiva. São Carlos: Pedro \& João, 2007. p. 13-31.

INDURKY, Freda. A fragmentação do sujeito em análise do discurso. In: INDURSKY, Freda. \& CAMPOS, Maria do Carmo. (orgs) Ensaios: discurso, memória, identidade. Porto Alegre, Ed. Sagra Luzzatto: 2000.

PÊCHEUX, M. (1969). Por uma análise automática do discurso. In: GADET, F. \& HAK, T. (orgs.). Análise do discurso: uma introdução à obra de Michel Pêcheux. Campinas, SP: Editora da UNICAMP, 1997, p.61-89.

(1975). Semântica e discurso: uma crítica à afirmação do óbvio.

Campinas, SP: Editora da UNICAMP, 1995. 
ABSTRACT: Following the prospect of French analysis of speech, reflect on how the constitution of the senses, from different interpretations of the law on adoption by homosexual couples and their relationships to the social events. The analysis illustrates the conflicts between the application of legal standards in the social sphere and heterogeneity of constitutive interpretation, which works on top not only the discourse of normalization, but in any event discursive.

Keywords: law; FD; subject-positions ; event. 